\title{
Casos clínicos del mundo real para mejorar la Ciencia, el Arte y la Artesanía de la Medicina, y hacerla más sostenible
}

Un dilema recorre la Medicina desde hace más de dos siglos...

[... en la segunda mitad de la década de 1830 en la Academia de Medicina de París flotaba la siguiente pregunta: ¿el quehacer del clínico debe girar en torno al paciente individual de carne y hueso o a un hipotético enfermo resultado del cálculo de probabilidades?

Detrás de esta cuestión lo que se estaba ventilando era ni más ni menos saber cuál debía ser el papel de la profesión médica en la sociedad... si el médico debía ser un sanador humanitario o, por el contrario, un científico empírico.

Este dilema suele traerse a los debates sobre la humanización de la asistencia; por ejemplo, cuando se habla de la «medicina basada en la afectividad» que diría Jovell ${ }^{2}$, en contraste con la efectividad. Pero también puede servirnos para una reflexión de corte epistemológico. ¿Ha de apasionarnos la diabetes o el diabético?

La principal corriente de pensamiento médico siguió por el primer camino, para pertrecharse de una base científica y competir con otras disciplinas. El desafío estribaba en conectar un concepto abstracto de enfermedad con el caso de un paciente concreto: si yo puedo predicar que esta paciente mía tiene una diabetes, le podré aplicar todo el conocimiento global acumulado en su beneficio; y también, la experiencia del tratamiento a mi paciente podrá alimentar el conocimiento general. De ahí la trascendencia de la nosología y el diagnóstico para la medicina clínica.

Los debates sobre si la medicina es una ciencia o un arte son abundantes y poco concluyentes, pues acaban reparando en que ambos elementos son esenciales ${ }^{3}$. Quizás sería más fácil si distinguiéramos entre Medicina (como disciplina del conocimiento que estudia la enfermedad) y Práctica Clínica (como desempeño profesional de servicio al paciente).

Con esta diferenciación sería más fácil entender la conocida frase de Osler: «la medicina es la ciencia de la incertidumbre y el arte de la probabilidad» ${ }^{4}$. La incertidumbre debe ser abordada con el método científico para despejar en lo posible la ignorancia, las falacias y los sesgos; y en la práctica clínica hemos de usar la probabilidad para hacer todo el bien posible a nuestro paciente, y evitarle todo el mal que se pueda anticipar.

En todo caso, el componente científico de la Medicina se va construyendo generación a generación, con un método inductivista (desde la experiencia concreta hacia su generalización), con aportaciones de otras ciencias y con una interacción entre múltiples saberes; todos ellos influidos por los determinantes culturales y de los paradigmas científicos de cada momento. Como el resto de las disciplinas científicas, su escrutinio crítico desvela la provisionalidad y limitación del saber, pero también muestra la grandeza de cuestionar permanentemente las ideas, teorías, constructos y métodos de cada tiempo y lugar.

La Práctica Clínica tiene un aspecto instrumental que la conecta con el repositorio de conocimientos que atesora la Medicina: el «reconocimiento de patrones» permite enlazar lo particular y tangible (anamnesis, exploración, pruebas, etc.) con lo general y abstracto. Los estilos de práctica de centros, especialidades y médicos concretos muestran gran variabilidad en el carácter más amplio y con- cienzudo, o más focalizado y expeditivo con el que resuelven la conexión entre paciente y morbilidad. Obviamente, con la masificación y la reducción del tiempo clínico hábil, la visión clínica se torna más lineal, estrecha y miope.

Pero el arte de la Práctica Clínica va mucho más allá: la información recogida del paciente nos habla de muchas dimensiones que no vienen recogidas en la abstracción nosológica. Un buen médico sabe usarla para ajustar el proceso de tratamiento y cuidados, de forma que elabore un «traje a medida». Sin embargo, este ajuste virtuoso no es fácil de abstraer, generalizar y comunicar.

El método tradicional de hacerse médico es acompañar y observar; el aprendiz va impregnándose de la praxis de su maestro clínico y así adquiere una serie de competencias complejas, embebidas en las múltiples dimensiones de la interacción clínica. «Siga a esa bata» sería la frase que simboliza la esencia del «Sistema MIR» de formación de especialistas.

Pero el método del aprendiz y el maestro tiene un alcance muy limitado. Extenderlo es esencial para que la excelencia en el arte puede divulgarse ampliamente; y también para que las dimensiones extra-nosológicas de los casos clínicos tengan posibilidad de enriquecer el tapiz de la buena medicina. Esta sería la importante contribución de la publicación de «casos clínicos» en revistas de medicina: ensanchar y enriquecer el conocimiento existente, así como mejorar patrones de respuesta cotidiana de los médicos en su práctica clínica.

Al analizar un caso clínico, la realidad se cuela por todos los poros: determinantes sociales de la salud, medios asistenciales disponibles, comorbilidades y complicaciones, dilemas éticos, comportamientos y preferencias de los pacientes, problemas de calidad, de seguridad, de costes... Y, además, al tener que formalizarlo como publicación científica el autor se obliga a una conexión más fuerte y sistemática con los conocimientos existentes en la Medicina y su relación con otras ciencias. De este ejercicio puede surgir una modulación o matización del saber existente, o incluso un cuestionamiento de conceptos dominantes.

En el falsacionismo de Popper solo hace falta un «cisne negro» para impugnar la aseveración de que «todos los cisnes son blancos»; quizás es más apropiado, siguiendo a Lakatos, decir que las evidencias contrarias al pensamiento dominante debilitan este (más que lo impugnan o falsean).

El principio de realidad entra a complementar la «ciencia médica» y ayuda a que otros aprendan a mejorar la práctica clínica por analogía con los elementos que se muestran y analizan en los casos.

En esta línea convendría situar la práctica clínica en una encrucijada:

a) Entre lo que potencialmente cabría hacer por un paciente: impacto potencial de la Medicina y su traducción como necesidades de salud (ability to benefit o margen óptimo de ganancia de salud).

b) Los recursos y competencias que realmente se puede ofrecer en un lugar y momento dados (oferta local de centros, servicios, equipos profesionales, tecnologías, y capacidades movilizables para un paciente concreto en un espacio y tiempo específico)

c) Y lo que es conveniente, aceptable y apropiado para el paciente (demandas, expectativas y preferencias del paciente). 
Entre los tres polos a conciliar que muestra la Figura 1, el médico clínico actuaría como intermediario, bróker o conector entre necesidad, oferta y demandapreferencias. De este equilibrio surgiría el concepto de variabilidad apropiada de la práctica clínica, y este es el ajuste final de la gestión clínica que produciría efectividad, seguridad, calidad y satisfacción; y en muchos casos posiblemente eficiencia, dado que la buena medicina clínica tiende a evitar las desmesuras diagnósticas estériles, el intervencionismo disruptivo frecuentemente y (yatrogénico) y la obstinación terapéutica inclemente.

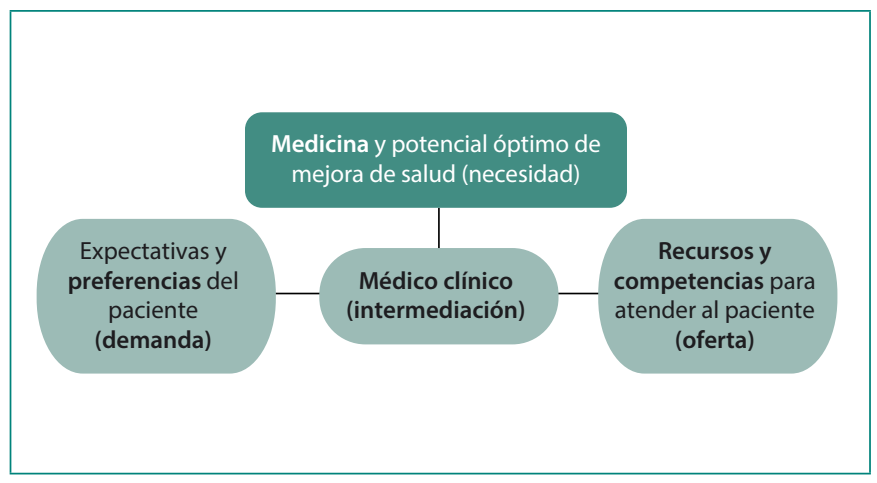

Figura 1. El médico clínico como intermediario que gestiona el equilibrio entre necesidades, ofertas y demandas-preferencias de los pacientes.
Toda esta riqueza se puede difundir en buenos casos clínicos publicados; el método casuístico, bien enraizado en la reflexión crítica de la evidencia, muestra un innegable valor para estudiar y mejorar el manejo de la complejidad (bio-psico-social) $^{6}$.

La frase de Osler se podría complementar con una dimensión que es más difícil de enseñar y difundir: la «Artesanía de la Compasión». Al «padecer con» el enfermo a lo largo de su enfermar, tejemos pacientemente en su urdimbre personal la trama de nuestro compromiso vital, para crear el tapiz único que muestra la excelencia de la medicina como conjunción del saber y la misericordia. Las reflexiones de los maestros sabios de la medicina clínica nos pueden inspirar una visión que mitigue los problemas de una práctica inapropiada (lo innecesario, inútil, inseguro, inclemente o insensato)?

El testimonio del neurocirujano Marsh ilustra bien esta afirmación, que revindica la importancia de una práctica clínica consciente y reflexiva, que está en las antípodas de la rutinaria aplicación lineal del saber de la Medicina a casos concretos ${ }^{8}$.

Uno puede pensar que la operación ha sido un éxito porque el paciente sale con vida del hospital, pero, años después, cuando ves a esa persona -como me ha pasado muchas veces-, comprendes que el resultado de la intervención fue un desastre absoluto desde el punto de vista humano... ahora estoy más dispuesto a aceptar que dejar morir a alguien puede ser una opción mejor que operarlo cuando solo hay una posibilidad muy pequeña de que esa persona pueda volver a valerse por símisma.

José Ramón Repullo-Labrador Profesor y Jefe del Departamento de Planificación y Economía de la Salud. Escuela Nacional de Sanidad. Instituto de Salud Carlos III, Madrid, España.

jrepullo@isciii.es

Citar como: Repullo-Labrador JR. Casos clínicos del mundo real para mejorar la Ciencia, el Arte y la Artesanía de la Medicina, y hacerla más sostenible. Rev Esp Casos Clin Med Intern (RECCMI). 2020 (Dic); 5(3): 103-104. doi: 10.32818/reccmi.a5n3a1.

Cite this as: Repullo-Labrador JR. Real world clinical cases to improve the Science, Art and Crafts of Medicine, and make it more sustainable. Rev Esp Casos Clin Med Intern (RECCMI). 2020 (Dec); 5(3): 103-104. doi: 10.32818/reccmi.a5n3a1.

\section{Bibliografía}

1. Puerta JL. De lo universal a lo particular. Ars Medica. Revista de Humanidades 2006; 5(1): 1-5.

2. Jovell AJ. Medicina basada en la afectividad. Med Clin (Barc). 1999; 113(5): 173-5.

3. Herman J. Medicine: the science and the art. Med Humanit. 2001; 27(1):426. Disponible en: http://mh.bmj.com/content/27/1/42.full. (Último acceso octubre 2020).

4. Quote-tab. William Osler quotations. Disponible en: https://www.quotetab. com/quotes/by-william-osler. (Último acceso octubre 2020).

5. Álvarez JF. Zamora Bonilla J. Filosofía de la ciencia: el conocimiento científico [Internet]. Madrid: Escuela Nacional de Sanidad; 2014 (consultado 3/11/2020). Tema 15.8. Disponible en: http://e-spacio.uned.es/fez/eserv/ bibliuned:500980/n15.8_Filosof_a_de_la_ciencia.pdf.
6. Arellano JS, Vélez-Vega J. De la ética constructivista social a la casuística: Los principios prima facie José Salvador Arellano Jorge Vélez Vega. En: Hall RT, Arellano JS (eds). La Casuística: Una metodología para la ética aplicada. [Edición Internet] 2013. 174-190. Disponible en: http://unidadbioetica. com/libros/Casu\%C3\%ADstica.pdf (consultado 3/11/2020).

7. Repullo JR. Taxonomía práctica de la «desinversión sanitaria» en lo que no añade valor, para hacer sostenible el Sistema Nacional de Salud. Rev Calid Asist. 2012. 27 (3): 130-8 Disponible en: https://www.elsevier.es/es-revista-revista-calidad-asistencial-256-articulo-taxonomia-practica-desinversion-sanitaria-lo-S1134282X12000413. (Último acceso octubre 2020).

8. Marsh H. Ante todo no hagas daño. Ed. Salamandra. 2016. Reflexiones del neurocirujano Henry Marsh recogidas y traducidas por Rodrigo Gutiérrez. Disponible en: http://www.regimen-sanitatis.com/2016/12/henry-marsh-una-antologia-i.html. 